\title{
Financial Contagion During the European Sovereign Debt Crisis
}

\author{
Dieter Smeets $\mathrm{a}^{*}$ \\ a University of Duesseldorf, Universitaetsstrasse 1, D-40225 Duesseldorf, Germany \\ *Corresponding author's email address: smeetsd@uni-duesseldorf.de
}

\section{A R T I C L E I N F O}

Received: $10-12-2015$

Accepted: 01-02-2016

Available online: 07-05-2016

Keywords:

Crisis news;

Financial contagion;

GARCH models;

Sovereign debt crisis.

JEL Classification:

F34; F36; G01; H63.

\begin{abstract}
A B S T R A C T
From early 2010, the Euro Area has faced a severe sovereign debt crisis. I use multi- and univariate EGARCH-models to assess whether contagious effects are identifiable during this crisis, or whether countries' problems are instead due to fundamental problems founded in the affected economies themselves. The multivariate analysis reveals a generally decreasing co-movement of government bond returns which increased only temporarily. In contrast, the univariate analysis is directed more to detecting channels of contagion. The analysis of rating announcements concerning Greece as well as crisis news in general, reveals that there are some evidences for mean and volatility contagion.
\end{abstract}

(C) 2016 The Authors. This is an open access article under the terms of the Creative Commons Attribution License 4.0, which allows use, distribution and reproduction in any medium, provided the original work is properly cited.

DOI: http://dx.doi.org/10.18533/jefs.v4i02.199

\subsection{Introduction}

Since spring 2007, difficulties in a small segment of the American mortgage market (subprime loans) led to a strong increase of payment defaults, a reassessment of (securitised) loans and the closing of credit-portfolios, which reached its peak in the demise of Lehman Brothers in September, 2008. However, the initial financial crises were not to be confined only to the financial markets but, in autumn 2008, spread increasingly to the real economy, and eventually leading to the most serious recession many countries have seen since the Second World War. In addition, extensive rescue programmes, state guarantees and recession-induced tax losses in some countries, in turn, caused exploding government deficits and steadily increasing debt ratios.

The first European country hit by the emerging debt crisis was Greece. On the 23rd of April 2010, the Greek government requested official help from the (remaining) euro-area member countries as well as the International Monetary Fund (IMF), which was subsequently provided by both in the form of rescue loans to the sum of 110 billion euros. However, on the 9th of May 2010, and in the space of just one week, both the euro-area member countries and the IMF agreed on a further 750 billion euro rescue fund (EFSF) in preparation to support additional countries. Ireland was the first country to draw on this fund at the beginning of December 2010, to the amount of about 85 billion euros. Portugal then followed in May 2011, with a further 78 billion-euro supplication.

Besides the financial aid culminating (up to now) in the permanent European Stability Mechanism (ESM) with an actual volume of 500 billion euros, numerous other measures were taken to overcome the current crisis, or to 
avoid new crises. In addition to fiscal policy, the European Central Bank (ECB) has become increasingly engaged in rescue operations, in particular by purchasing government bonds of threatened member countries. Many of these measures were justified - at least partially - as a means of trying to avoid the dangers of contagion.

Against this background, we empirically analyse the possible emergence of (financial) contagion during the government debt crisis. The study is restricted, however, to immediate contagion effects via the yields of government bonds, and does not assess the spread of any corresponding effects e.g. through the national banking systems (Mink and de Haan, 2012). To detect contagion effects we apply both multivariate and univariate EGARCH models. On one hand, this class of models allows an appropriate correction of correlation coefficients by a varying variance, while on the other allows a distinction to be made between mean and variance contagion. The analysis focuses on the most crisis-ridden Euro member states - Greece, Ireland, Portugal, Italy and Spain - as well as Germany and Austria which have remained comparatively unaffected by the crisis. The results of our multivariate EGARCH models between Greece and each of the other countries under consideration reveal a decreasing correlation between government bond yields in general, with some rare phases of temporary increases which may be interpreted as contagion. The highest level of correlation can be observed in all cases around the dispense of the first Greek rescue package in May 2010. While the multivariate EGARCH models focus on contagion in general, the univariate EGARCH models are devoted more to the channels of transmission. There is some evidence for mean and variance contagion which is consistent with the risk-premium, the liquidity as well as the correlatedinformation channel.

The paper is organised as follows: We first provide an overview of the literature on contagion and the econometric methods used to detect it. In Section 3 the model structure for the empirical analysis comprising uni- and multivariate GARCH models, as well as the data, are explained. Section 4 presents our empirical results and some corresponding interpretation. Finally, Section 5 summarises our results and provides some policy implications.

\subsection{Literature review}

\subsection{Literature on (financial) contagion}

In recent years, the topic of contagion has received high attention in the context of currency and banking crises, thus, only a brief overview about the corresponding results should be given here. According to Dornbusch et al. (2000, p. 178) contagion is best defined

"... as a significant increase in cross market linkages after a shock to an individual country (or group of countries), as measured by the degree to which asset prices or financial flows move together across markets relative to this co-movement in tranquil times ....".

Starting from this general definition, Pericoli and Sbracia (2003) have compiled five most commonly used criteria from the literature to identify contagion:

1. The probability of a crisis in one country rises as a response to a crisis in another country.

2. An increase in volatility is cross-national.

3. A co-movement of asset prices cannot be explained by fundamental factors.

4. The correlation of financial markets between countries increase significantly.

5. Due to a crisis, the transmission mechanism changes and subsequently causes the adjustment of (cross-country) financial relations.

Moreover, two additional criteria can be found in the literature:

6. The events which cause contagion reflect negative extreme values.

7. The transmission of contagion effects is sequential, for example in a causal sense.

However, there is no agreement over which of these specific criteria are necessary or sufficient to characterise contagion. A more detailed analysis of contagion is therefore based on the identification of causes or transmission channels through which a crisis is transmitted across countries. Nonetheless, even the latter are defined differently in the literature.

An initial distinction can be made between cross-country external shocks, which affect (in the form of a crisis) several countries simultaneously ("common cause"), and country-specific crises, which spread to other countries. Cross-country shocks can appear, for example, in the form of interest or policy changes in large (industrial) countries as well as in the form of changing commodity prices (e.g. oil price shocks). Nevertheless, the discussion about different transmission channels centres on country-specific crises, which spread either through fundamental factors or through (pure) contagion effects. Such a distinction can be found, for example, in Masson 
(1999), Dornbusch et al. (2000) as well as Forbes and Rigobon (2002). It additionally forms the basis of the following Figure 1.

Figure 1: Transmission channels of crises

Interdependence through fundamental factors can, in turn, be traced back to real or financial dependencies (e.g. Fratzscher, 2003). With the real interdependence - in particular with currency crises - trade links may be the most important. A depreciation of a country's currency typically diverts trade due to higher international competitiveness which is to the disadvantage of other countries and leads to decreasing demand.

Conversely, financial dependencies can originate from the fact that several countries have reached a state of debt with an unique (international) investor, whose reaction to the crisis of one country also influences other countries $^{1}$. This is a possible result of crisis-induced liquidity problems or the restoration of an optimum risk diversification. Such a portfolio restructuring can be triggered for institutional investors by rating-regulations, which must be complied to. Subsequently, falling asset prices in one country can lead to sales reactions in other markets and countries, particularly if their ratings are also expected to be downgraded under a certain threshold. However, in this case the asymmetrical distribution of information plays no role for contagion. Here, instead, it is simply the "news" in the form of the rating by an informed intermediary that shakes up the capital markets and triggers the "wake up call" (Goldstein, 1998). The transmission channels explained up to this point - as being induced by fundamental factors - are termed by part of the above mentioned authors not as "contagion", but rather as "interdependence" or "spillovers".

In contrast, as (pure) contagion they only interpret those transmission mechanisms which are not due to changes of fundamental factors. The herding behaviour of investors - as induced by asymmetrical distribution of information - also plays a decisive role. This may result in self-fulfilling prophesies, which are not justified by fundamental factors. With perfect information, however, no contagion effects would occur. Furthermore, in this connection it is also pointed to the "wake up call" which now leads - despite heterogeneous fundamentals - to the fact that certain countries are regarded as homogeneous (crisis) group and, hence, capital is drawn off in crisis situations (although unwarranted by the fundamentals) from all countries belonging to this group.

Dornbusch et al. (2000) include under this last point the influence of changed economic conditions ("changes in the rule of the game") on investors' decisions. If these changes are of a supranational nature, however, they can also be interpreted as cross-country shocks. Other reasons for contagion based on investors' behaviour particularly in connection with banking crises - were discussed in Chen (1999), Allen and Gale (2000 and 2004) as well as Brunnermeier and Pedersen (2007).

Since fundamental factors and pure contagion can barely be differentiated in the propagation of shocks through the financial sector, an alternative clustering identifies major channels of financial contagion ${ }^{2}$ as the:

- Correlated-information channel,

- Liquidity channel and

- Risk-premium channel.

1 The importance of financial linkages and leveraged banking systems is recently highlighted by Forbes (2012) as well as Gorea and Radev (2013).

2 For a more detailed analysis compare for example Longstaff (2010) as well as Leung and Taylor (2013). 
This distinction points primarily to the source of contagion and less to the difference between interdependence and contagion. For instance: The existence of a common creditor alone cannot explain how a crisis comes into being and spreads across nations. It is only if this common creditor changes his expectations that a crisis may arise. The remaining difference may then boil down to whether these expectations were formed rationally or irrationally.

Most of the theoretical contributions to the literature on contagion originates from the analysis of currency crisis. The challenging difference between a currency crisis and a sovereign debt crisis is, however, that the former is typically a one-shot event while the latter may be an ongoing event with both calm and turbulent phases, frequently intertwined with banking crises.

According to Kaminsky, Reinhart and Vegh (2003) there may, therefore, be crisis phases during which contagious effects occur, and others without any reaction. They focus on "fast and furious contagion episodes" which:

- Follow a large surge in capital (in-)flows,

- Emerge as a surprise, and

- Involve a leveraged common creditor.

It is only if this "unholy trinity" coincides that contagion is likely to occur. However, in the event of a government debt crisis especially, the first two conditions might only be met during the early phase. Following this, capital will instead outflow and a sovereign bankruptcy appear no longer incredible.

\subsection{Empirical studies}

With the basic definition of contagion outlined as a significant increase in cross market linkages, correlation analysis seems best suited to examine this phenomenon empirically. A difficulty arises, however, in that the correlation coefficient $(\rho)$ depends on the standard deviation in the markets involved ( $\sigma_{\mathrm{x}}$ and $\sigma_{\mathrm{y}}$ ) and that these standard deviations typically increase during crises.

$$
\rho=\beta \frac{\sigma_{x}}{\sigma_{y}}
$$

where $\beta$ represents the coefficient of a regression of $y$ on $x$ (Baur, 2003, p. 409).

Nevertheless, early empirical contributions to the literature on contagion (for example King and Wadhwani, 1990) are based on simple correlations without controlling for the change in volatilities. Over the course of time, various methods have been suggested to account for this notable drawback. Only Chiang et al. (2010), however, started indentifying contagion by estimating a multivariate GARCH model.

Until now, only a few empirical studies have analyzed contagion within the context of the European sovereign debt crisis. One of these is Missio and Watzka (2011), who also based their analysis on multivariate GARCH models. Their period of investigation ends, however, at the first quarter of 2011. In the course of their study they find some indication of contagion, especially during the summer of 2010, the first phase of the crisis. Given the discussions of these studies as well as the general literature on multivariate GARCH models ${ }^{3}$ it can be concluded that this class of models take into account the afore mentioned drawbacks as well as problems and, thus, seems most appropriate to empirically evaluate contagion (Missio and Watzka, 2011, p. 6).

Estimating a GARCH model further allows us to distinguish between mean- and volatility-contagion. Mean contagion is existent if the government bond return in one country increases due to the sovereign debt crisis in another country (Greece). Conversely, volatility contagion means that an increased volatility in one market is propagated to corresponding markets in other countries. Since the measure of volatility (the variance) is always positively defined it is unclear whether or not it reflects an (unique) upward or downward risk for a certain country over a specific period. Increased volatility will in most cases be due to the news (concerning a crisis) that the market participants are faced with.

The most recent study on contagion during the European debt crisis was presented by Caporin et.al. (2013). By using different techniques to detect contagion between 2008 and 2011 they reveal a change in the intensity of the propagation of shocks where the movement of coefficients is in a downward, rather than upward, direction. From this result, they conclude that contagion up to this point has remained subdued.

\footnotetext{
3 There exists a large body of literature concerning MGARCH models which can not be quoted here. However, a good summary can be found in Bauwens et al. (2006).
} 


\subsection{Model specification and dataset}

\subsection{Univariate GARCH models}

Based on the original work of Engle (1982) and Bollerslev (1987) generalised autoregressive conditional heteroskedastic (GARCH) models have become the fundament of the dynamic volatility models (Alexander and Lazar, 2006). In the subsequent empirical section we apply an exponential GARCH (EGARCH) model as proposed by Nelson (1991). This is based on the pure GARCH model, but includes several advantages in comparison: Firstly, it allows the incorporation of an asymmetric response of the volatility to shocks. Secondly, there is no longer any need to artificially impose non-negativity constraints on the parameters because even if they are negative, $\sigma^{2} \mathrm{t}$ in equation (3) will be positive. Thirdly, the stationarity restriction is reduced to $\beta_{1}<1$ in equation (3).

Our univariate estimates are therefore based on the following $\operatorname{EGARCH}(1,1)$ model structure, where $r_{j, t}$ represents the bond return at time $t$, and subscript $\mathrm{j} \in$ \{Greece, Germany, Portugal, Ireland, Italy, Spain, Austria\}.

$r_{j, t}=\alpha_{0}+\sum_{k=1}^{n} r_{j, t-k}+$ Rat $_{t-1}+$ Event $_{t-1}+u_{t}$

$\log \left(\sigma_{j, t}^{2}\right)=\beta_{0}+\beta_{1} \log \left(\sigma_{t-1}^{2}\right)+\beta_{2}\left[\frac{\left|u_{t-1}\right|}{\sqrt{\sigma_{t-1}^{2}}}-\sqrt{\frac{2}{\pi}}\right]+\beta_{3}$ Event $_{t}$

$\sigma_{t}^{2}$ denotes the conditional variance since it is the estimate for the variance one period ahead, calculated from any past information deemed relevant. It can be interpreted as the weighted function of a long-term average value $\left(\beta_{0}\right)$, information about the fitted variance from the model during the previous period $\left(\sigma^{2} \mathrm{t}-1\right)$ as well as about the volatility during the previous period ( $\left.\mathrm{u}_{\mathrm{t}-1}\right)$ (Brooks, 2009, p. 123).

In addition to the previously defined variables, Rat is a dummy for rating announcements regarding Greece, and

Event a dummy for policy events regarding the sovereign debt crisis in general. Rat and Event-lagged one period - both enter the mean equation (2) as an explaining variable while only Event $\mathrm{t}$ is included in the variance equation (3). Furthermore, in the mean equation concerning Greece another specific dummy is included to capture the structural break following the hair-cut in February 2012. In almost all cases $\mathrm{k}$ in equation (2) is equal to 1 , so in general we estimate an $\operatorname{AR}(1)-\operatorname{EGARCH}(1,1)$ model. The only exceptions are Italy where $\mathrm{k}=2$, and Austria where $\mathrm{k}=0 . \alpha$ again represents the "GARCH" effect which can be explained as magnitude or symmetric effect of the model while $\beta_{1}$ measures the persistence in conditional volatility (Alexander, 2009). If $\beta_{1}$ has a relatively large value in comparison to $\beta_{2}$, the volatility takes a long time to die out following a shock to the market.

\subsection{Multivariate GARCH models}

Multivariate GARCH models bare considerable similarity to univariate ones, except that the former also specify equations for how the co-variances move over time. Multivariate GARCH (MGARCH) models can primarily be distinguished according to their modelling of the covariance equation (for an overview see Bauwens et al., 2006). Various methods were suggested in the literature which include the diagonal VECH, the Constant Correlation (see for example Bollerslev, 1990), and the Dynamic Conditional Correlation (see for example Engle and Sheppard, 2001 as well as Engle, 2002). In order to discriminate between tranquil and contagious phases, the (changing) pattern of the conditional correlation coefficient over time must be observed. Therefore, our analysis is based on the dynamic conditional correlation method (DCC) as suggested by Engle (2002). Moreover, the individual building-blocs of the MVGARCH system correspond to EGARCH(1,1) specifications, as explained before, which model the log of the variance rather than the level. Consequently, there is no need to artificially impose nonnegativity constraints on the parameters of the variance equations. Against this background, time-varying conditional correlation coefficients between each country under consideration and Greece were calculated in accordance with the above explanation.

\subsection{Dataset}

In order to detect contagious effects during the current crisis our analysis is based on a sample of seven countries: Austria, Germany, Greece, Portugal, Ireland, Italy and Spain. This sample includes both countries that witnessed refinancing problems resulting from increased government bond yields, as well as countries which have, by and large, not been negatively affected by the crisis. Throughout the analysis Greece is considered the origin of possible contagion effects because it was first to be hit by the sovereign debt crisis. 
The dataset consists of the 10-year benchmark government bond yields ${ }^{4}$ provided by Thomson Reuters EcoWin for the time period from 10/01/2009 until 11/30/2012. Using daily returns, the sample covers a total of 819 data points. The benchmark yield represents that interest rate, which countries have to offer for newly emitted 10 -year government bonds in order to attract investors.

Moreover, two dummy variables are constructed: One representing the rating announcements on Greece, while the second captures "events" concerning individual crisis countries and the debt crisis in general [e.g. policy (re)actions]; both reflecting (new) information that the market participants are faced with. The rating-dummy takes a value of one for each day that Fitch, Moody's or Standard and Poor's announced a downgrade on Greece's rating, and zero otherwise. The event-dummy correspondingly takes a value of one for each day(s) when news was published or, for instance, the heads of state and government of the EU met to debate (further) actions to combat the crisis. The rating-dummy comprises a total of 21 Greek downgrades by the leading rating agencies, while the event-dummy consists of 22 events. Both these dummies are compiled and further explained in the appendix. Moreover, for all analyses covering the date of the Greek haircut $(02 / 22 / 2012)$ an additional dummy is included in the mean equation concerning Greece, which is equal to one only for the date of the haircut and zero otherwise. This dummy accounts for the structural break which occurred at this point in time.

The univariate EGARCH analysis covers different time periods. The "basic" period spans the time from $10 / 01 / 2009$ to $06 / 30 / 2012$ and is not especially marked. Period 2 is the period from 10/01/2009 to $02 / 29 / 20012$ and is marked with a (k), except Ireland, where the short time period (k) contains data from $10 / 01 / 2009$ to $08 / 09 / 2011$. The longest period contains data from $10 / 01 / 2009$ to $11 / 30 / 2012$ and is marked with (l), and is applied to those countries which have come into trouble comparatively late.

All empirical models are based on an EGARCH(1,1) model. In all cases the individual models are checked for asymmetric effects as well as for alternative distributions of the variance. These effects are incorporated in those cases where corresponding coefficients are significantly different from zero by at least five percent.

Moreover, in the univariate models we include the event- as well as the rating-dummy (lagged one day) within the mean equation. The event-dummy is also used in the variance equation. Any other affiliations did not reveal significant effects and are, therefore, not presented here. All models are carefully checked for remaining autocorrelation and ARCH effects. These tests are based on the standardised residuals using the Portmanteau test (Q20) to detect remaining autocorrelation in the mean equations, and on the squared standardised residuals using the Portmanteau test (QQ20) as well as Engle's LM test (ARCH20) to check for remaining ARCH effects in the variance equations.

Further, ADF and KPSS tests - not presented here - are conducted for each of the time series involved in the study. As all series proved to be integrated of order one, the entire analysis is based on first differences of government bond returns.

\subsection{Empirical results}

Using our multivariate EGARCH model(s) as specified above, the correlation series are calculated and displayed in the next section. Since Greece was the first country witnessing debt problems we examine in pairs the dynamic correlations between Greece as well as Ireland, Portugal, Spain, Italy, Germany and Austria, in order to detect financial contagion. Although there have been several countries in turmoil during the European sovereign debt crisis, the starting point of the crisis was undoubtedly Greece. Moreover, most of the general crisis reactions such as the establishment of the EFSF and the ESM, for example - had its origin in the Greek development. Therefore, it seems appropriate to regard Greece as being the "ground zero" for the contagious effects.

\subsection{Multivariate analysis}

To start with, all figures are built alike and contain in addition to the time-varying correlation coefficient events concerning the Greek debt crisis below each chart. This practice is necessary to separate the increased correlation due to Greek shocks from those increases which arise during normal (tranquil) phases. Since contagion is defined as a significant increase of market linkages, as measured by the degree at which asset prices move together (see definition page 4 ), only a positive and increasing correlation corresponds to contagion.

\footnotetext{
4 We decided to use bond yields instead of CDS premia in our analysis because the latter capture only the default risk while bond yields additionally incorporate credit spread risk, downgrade risk, liquidity risk as well as general risk aversion. Nonetheless, there is a high correlation between both these series (Barrios et al., 2009). Furthermore, the use of yield spreads against German government bonds was discounted as a starting point in order to highlight the differences between crisis and non-crisis countries.
} 
Therefore, possible contagious effects are restricted to the period between 2009, quarter 4, and 2012, quarter 2 . This is because the first signs signalling a Greek crisis were connected to the new budgetary figures announced by the new government of George Papandreou on October 20th, 2009. High, and in some cases even increasing, correlation coefficients during the first three quarters of 2009 are therefore interpreted as "normal" linkages and not as contagion. Since the third quarter of 2012 there is, again, an increase in correlation coefficients to be observed. In this case, the general decline of interest rates is reflected as a result of the address made by European Central Bank President, Mario Draghi, stating that policy makers (in particular the ECB) will do whatever is needed in order to preserve the euro. The result can be interpreted as a common external shock which hits all countries under consideration in a positive way. Subsequently, we restrict our analysis of identifying potential contagion effects between countries to the period stated above.

Between 2009, quarter 4, and 2012, quarter 2, in all cases, there is a trend of generally decreasing correlation to be observed between Greek returns and those of the other countries under consideration. What is more, Germany even exhibited a negative correlation against Greece, showing the flight to quality towards German government bonds. The same holds true, with some reductions, for Austria. Accordingly, Germany, and even Austria, did not exhibit contagion as defined above between autumn 2009 and August 2012.

While the declining trend in correlation coefficients shows that (crisis-) countries underwent specific developments during this phase, there are still a few temporary phases of strongly increasing positive linkages which may be interpreted as contagion. In addition, all crisis pairs show that the strongest increase and highest level of correlation occurred during the weeks before the agreement of the first Greek bail-out. This development is particularly obvious for Ireland and Portugal, the first countries to follow Greece into the crisis. The excessive high correlation during the first phase of the crisis (2010, quarter 2, reflecting the first Greek bail out) may further point towards the workings of a "wake up call". New information may have prompted investors to reassess the vulnerability of other countries, which thereby spreads the crisis across borders. Economic news signals information relevant for other markets and countries - in particular, that even European countries may fall bankrupt, and that default risks for countries facing similar situations require adjustment. This result is consistent with recent studies by Giordano et al. (2013) as well as Mink and de Haan (2012), which also found evidence of "wake up call" effects.

Moreover, the steady decrease of the correlation coefficient between autumn 2009 and summer 2012 strongly suggest that Greece is a special case which has caused contagion to spread across other countries, at worst, during few single phases of the crisis but developed in principal individually, and therefore apart from the other countries. There are only temporary increases connected with the shocks that originated in Greece. This result suggests that Greece in particular has exhibited an individual development over time, with only rare and temporary episodes when contagion may have occurred.

\subsection{Univariate analysis}

At this stage of the analysis we could proceed by basing our further estimates either on the correlation series of the multivariate models, or on (new) univariate models instead. We decided to apply the latter procedure for the following reasons:

- it avoids that misspecifications of the multivariate models is carried into the following analysis and

- it allows the distinction between mean- and volatility-contagion.

Table 1 summarises our univariate EGARCH results. The highlighted rows show those results which are important in assessing the extent of contagion. Firstly, successive rating downgrades regarding Greece significantly increased bond returns within Greece itself, but also in all other crisis countries. Moreover, those countries first hit by the crisis (Greece, Ireland and Portugal) were clearly more strongly influenced by Greek rating downgrades during the first phase as indicated by ( $\mathrm{k}$ ) in Table 1. Conversely, it is only the coefficients for Germany and Austria that are insignificant. During recent years there has been an upsurge of publications concerning the impact of rating announcements on the country immediately concerned as well as on other countries ${ }^{5}$. Although several authors arrived at the conclusion that rating downgrades in particular affect (home and foreign) financial markets, the channels of contagion have been less intensively elaborated upon until now ${ }^{6}$. An increase of government bond returns in one country due to a downgrade in another (foreign) country can, in principle, be consistent with all three channels of financial contagion previously discussed. These results may be explained by the risk-premium and the liquidity channel. On the one hand, there may be a general increase in risk premia which, nevertheless,

\footnotetext{
5 See for example DeSantis (2012), Caporin et al. (2012), Aretzki et al. (2011), European Parliament (2011), Afonso et al. (2010) as well as Reisen and von Maltzan (1999).

6 For an exception see Sy (2009).
} 
differ across countries. On the other hand, rating downgrades may be associated with capital losses which cause (common) creditors to reduce or rebalance portfolios and thereby transmit negative effects to other countries. It is also consistent with the correlated-information channel. If the rating downgrade is interpreted as news coming from an informed market participant it could spread to other countries existing in a similar fundamental situation.

Table 1: Empirical results

\begin{tabular}{|c|c|c|c|c|c|c|c|c|c|c|c|c|c|c|}
\hline & \multicolumn{14}{|c|}{ Country } \\
\hline & GRE & GRE (k) & IRL & $\operatorname{IRL}(\mathbf{k})$ & POR & POR (k) & ITA & ITA (I) & SPA & SPA (I) & AUT & AUT (I) & GER & GER (I) \\
\hline Mean-Equation & & & & & & & & & & & & & & \\
\hline constant & $0.02^{\star *}$ & $0.02^{\star *}$ & 0.00 & 0.01 & 0.01 & 0.01 & 0.00 & 0.00 & 0.00 & 0.00 & $0.00\left(^{*}\right)$ & $0.00^{\star \star}$ & 0.00 & 0.00 \\
\hline AR1 & $0.08^{* *}$ & $0.13^{* *}$ & 0.02 & $0.10^{*}$ & $0.10^{*}$ & 0.05 & $0.16^{* *}$ & $0.15^{\star \star}$ & $0.18^{* *}$ & $0.19^{* \star}$ & 0.00 & 0.00 & $0.18^{* *}$ & $0.17^{\star \star}$ \\
\hline AR2 & & & & & & & $-0.21^{* *}$ & $-0.18^{* \star}$ & & & & & & \\
\hline Rating GRI (t-1) & $0.07^{\star *}$ & $0.21^{* *}$ & $0.04^{*}$ & $0.10^{* *}$ & $0.05^{\star \star}$ & $0.07^{* *}$ & $0.02^{* *}$ & $0.02^{* *}$ & $0.02^{*}$ & $0.02^{*}$ & 0.01 & 0.01 & 0.00 & 0.00 \\
\hline Events (t-1) & $0.54^{\star \star}$ & $0.60^{* *}$ & 0.00 & 0.04 & -0.00 & -0.00 & $0.07^{*}$ & $0.09^{* \star}$ & 0.03 & 0.03 & -0.01 & -0.01 & $-0.03^{*}$ & $-0.03^{*}$ \\
\hline $\begin{array}{l}\text { Variance- } \\
\text { Equation }\end{array}$ & & & & & & & & & & & & & & \\
\hline constant & $-0.60^{\star *}$ & $-0.61^{* *}$ & $-0.61^{* *}$ & $-0.46^{\star \star}$ & $-0.63^{\star \star}$ & $-0.71^{\star *}$ & $-0.52^{\star *}$ & $-0.48^{* *}$ & $-0.67^{\star *}$ & $-0.60^{\star *}$ & $-0.37^{\star *}$ & $-0.33^{* *}$ & $-0.59^{\star \star}$ & $-0.57^{\star \star}$ \\
\hline $\mathrm{a}$ & $0.68^{\star \star}$ & $0.68^{* \star}$ & $0.47^{\star \star}$ & $0.37^{* *}$ & $0.46^{* *}$ & $0.50^{\star *}$ & $0.31^{* *}$ & $0.31^{* *}$ & $0.40^{* *}$ & $0.40^{* *}$ & $0.20^{* *}$ & $0.18^{\star \star}$ & $0.16^{* *}$ & $0.16^{\star *}$ \\
\hline b & $0.93^{\star *}$ & $0.94^{* *}$ & $0.93^{\star \star}$ & $0.95^{\star *}$ & $0.90^{* *}$ & $0.92^{* *}$ & $0.96^{\star \star}$ & $0.96^{* *}$ & $0.93^{* *}$ & $0.95^{\star \star}$ & $0.97^{\star *}$ & $0.97^{\star *}$ & $0.93^{* *}$ & $0.93^{\star *}$ \\
\hline Events & $1.04^{\star \star}$ & $1.10^{* *}$ & $0.65^{\star \star}$ & $0.91^{* *}$ & $0.62^{* *}$ & $0.75^{\star \star}$ & $1.13^{\star \star}$ & $1.03^{* \star}$ & $1.04^{\star \star}$ & $0.92^{* *}$ & $0.29^{*}$ & $0.32^{* *}$ & $0.51^{*}$ & $0.50^{* \star}$ \\
\hline Shape & & & $3.30^{\star \star}$ & $3.64^{* *}$ & $4.73^{\star \star}$ & $4.74^{\star \star}$ & & & $11.05^{\star \star}$ & $9.74^{\star \star}$ & $10.13^{\star \star}$ & $9.53^{\star \star}$ & & \\
\hline Q20 & 10.02 & 16.45 & 21.38 & 22.09 & 26.92 & 28.29 & 17.14 & 16.50 & 22.82 & 22.26 & 23.35 & 22.80 & 17.72 & 17.19 \\
\hline QQ20 & 3.10 & 11.14 & 17.60 & 13.71 & 27.12 & 27.74 & 22.48 & 23.89 & 26.92 & 25.73 & 11.40 & 12.28 & 10.46 & 9.81 \\
\hline ARCH2O & 0.15 & 0.51 & 0.82 & 0.68 & 1.30 & 1.36 & 1.05 & 1.12 & 1.31 & 1.26 & 0.50 & 0.54 & 0.51 & 0.48 \\
\hline
\end{tabular}

Notes: $\left.{ }^{* *},{ }^{*},{ }^{*}\right)$ indicates significance at the 1 percent, 5 percent or 10 percent level correspondingly.

Secondly, the impact of news is considered which reflects information resulting from various crisis-"events" concerning Greece in particular, but also Italy or the sovereign debt crisis in general. Therefore, the result that only Greek and Italian bond returns show significant coefficients points unambiguously to the fact that there are no mean-contagion effects via the correlated-information channel. Rather, that negative coefficients for Germany and Austria - being significant only in the case of Germany - may be due to the liquidity channel and a "flight to quality" effect ${ }^{7}$ as proposed by Brunnermeier and Pedersen (2007). This result is, in turn, consistent with our previous findings based on the multivariate analysis. It is those two countries which exhibit negative correlation coefficients, and lack significant increases during the crisis.

While there is no mean-contagion through the correlated-information channel we found, thirdly, strong evidence for volatility-contagion. Our news dummy reflecting crisis information explains significantly the (increased) volatility in all countries of our sample - independent of being a crisis country or not. This does not mean, however, that volatility increased in all countries by the same amount but rather that the individual increase is to a large extent due to the uncertainty before (and possibly even after) a crisis-"event".

Crisis-"events" accompanying new information (news) or (remaining) uncertainty concerning the "rules of the game" or the sovereign debt crisis in general include for example:

- the realization, that even European countries may fall bankrupt,

- raises the question of how many and which countries could ultimately be bailed-out,

\footnotetext{
${ }^{7}$ Audige (2013) arrives at a similar outcome.
} 
- the uncertainty of whether countries getting financial support will meet their obligations concerning reforms and

- the fear of a private sector involvement in necessary hair-cuts.

Based on an event study, Mink and de Haan (2012) also observe that news about the economic situation in Greece or a Greek bailout had an impact on Irish, Portuguese and Spanish bond rates.

While mean-contagion has a permanent impact on government bond returns volatility-contagion is, however, only a temporary phenomenon - even if it may last some time before the effects die out. Therefore, with a view to policy recommendations mean-contagion seems to be the more severe problem in this connection.

\subsection{Summary and conclusion}

In this study, both multivariate as well as univariate EGARCH models were estimated in order to analyse financial contagion during the European sovereign debt crisis and, in particular, the influence of rating announcements concerning Greece as well as political events. The multivariate EGARCH analysis reveals the correlation structure between Greece and all other countries under consideration. There is empirical evidence to suggest that over the crisis period included in this study, the (conditional) correlation coefficients show in nearly all cases a decreasing development with only temporary increases which are connected to special crisis phases in Greece. Moreover, the highest correlation coefficients could be observed in all cases around the first Greek bail-out in early 2010. This could be interpreted as the workings of a "wake up call" which brought awareness to the market participants that even European countries can fall bankrupt, and that investing in government bonds indeed involves a considerable risk (of default). Thus, after a rearrangement of portfolios, on average the correlation coefficients decreased steadily over time.

So, on the one side, our results correspond with those of Caporin et al (2013) in that we also find a generally declining trend in conditional correlation coefficients between the end of 2008 and autumn 2012. How ever, on the other side - and contrary to their results - we identified short periods of time during which the generally decreasing tend is interrupted by significant increases of correlation coefficients, that we were able to identify as contagion. Nevertheless, both studies show that contagion may have been, at worst, a temporary phenomenon which lost general importance over time, as can be seen from the declining level of correlation coefficients until autumn 2012.

While the multivariate EGARCH models were primarily devoted to detecting general contagion effects, the univariate models try to identify transmission channels of contagion. Moreover, this type of model enables us to distinguish between mean- and volatility-contagion. As evidenced by the study, mean-contagion in particular is caused by rating downgrades on Greece which spread to all other crisis countries. This is consistent with the workings of a liquidity- as well as a risk-effect. Crisis events and information, however, affect only the individually concerned countries with the exception of Germany and Austria which show negative coefficients. This points to the movement of a "flight to quality" during the crisis. Conversely, crisis events are highly responsible for volatility-contagion. Crisis induced increases in volatility can, in all countries, be significantly retraced - although to varying extents - to these crisis events and information. This may suggest the workings of a correlatedinformation effect.

In order to provide clear-cut policy recommendations, it would be necessary to draw an explicit distinction between interdependence or spillovers on the one hand, and (pure) contagion on the other. According to Forbes and Rigobon (2001), a country that suffers from financial contagion without having economically justified financing problems may reasonably call for some sort of bail-out mechanism. Our empirical results revealed, however, that not all the countries examined have been infected during the still continuing crisis, but only those which have already suffered from high indebtedness and considerable budget deficits. ${ }^{8}$. Consequently, contagion did not spread to countries like Germany and Austria. Against this background, possible contagion effects should not be prevented by bail-out actions of supra-national institutions like the EMS or the ECB but instead by a sustainable and convincing budgetary policy of the affected countries themselves. The finding of volatility- instead of mean-contagion through the correlated-information channel may also point to the fact that European crisis management have not been convincing, since crisis events mainly result in uncertainty.

In summary, we can conclude that there is some empirical evidence in favor of financial contagion during the sovereign debt crisis. It is ambiguous, however, as to whether these effects reflect a change in fundamentals or

8 The importance of fundamentals was also highlighted by Beirne and Fratzscher (2013). 
pure contagion due to irrational behavior instead. The answer to this question is, however, devoted to future research.

\section{References}

Afonso, A.; Furceri, D.; Gomes, P., (2011): "Credit ratings and the Euro Area sovereign debt crisis", ECB Working Paper 1347.

Alexandra, C., (2009): "Practical Financial Econometrics", John Wiley \& Sons, Ltd.

Alexander, C.; Lazar, E., (2006): "Normal mixture GARCH(1,1): Applications to foreign exchange markets", Journal of Applied Econometrics, Vol. 21 (2), 307-336. http://dx.doi.org/10.1002/jae.849

Allen, F.; Gale, D. (2000): "Financial Contagion", Journal of Political Economy, Vol. 108 (1), 1-33. http://dx.doi.org/10.1086/262109

Allen, F.; Gale, D. (2004): "Financial Intermediaries and Markets", Econometrica, Vol. 72 (4), $1023-1061$. http://dx.doi.org/10.1111/j.1468-0262.2004.00525.x

Arezki, R.; Candelon, B.; Sy, Amadou N. R. (2011): "Sovereign Rating News and Financial Markets Spillovers: Evidence from the European Debt Crisis", CESifo Working Paper 3411.

Barrios, S.; Iversen, P.; Lewandowska, M.; Setzer, R.(2009): "Determinants of intra-euro area government bond spreads during the financial crisis", European Commission, Economic Papers 388.

Baur, D. (2003): "Testing for contagion - mean and volatility contagion", Journal of Multinational Financial Management, Vol. 13, 405-422. http://dx.doi.org/10.1016/S1042-444X(03)00018-5

Beirne, J.; Fratzscher, M. (2013): "The pricing of sovereign risk and contagion during the European sovereign debt crisis", Journal of International Money and Finance, Vol. 34, 60-82. http://dx.doi.org/10.1016/j.jimonfin.2012.11.004

Bauwens, L.; Laurent, S.; Rombouts, J.V. K. (2006): "Multivariate GARCH models: A Survey" Journal of applied Econometrics, Vol. 21, 79-109. http://dx.doi.org/10.1002/jae.842

Bollerslev, T. (1987). "A Conditional Heteroskedastic Time Series Model for Speculative Prices and Rates of Return". The Review of Economics and Statistics, Vol.69 (3), 542-547. http://dx.doi.org/10.2307/1925546

Bollerslev, T. (1990): "Modelling the Coherence in Short-Run Nominal Exchange Rates: AMultivariate Generalized ARCH Model", Review of Economics and Statistics, Vol. 72, 498-505. http://dx.doi.org/10.2307/2109358

Brooks, C. (2008): "Introductory Econometrics for Finance", Cambridge University Press. http://dx.doi.org/10.1017/CB09780511841644

Brunnermeier, M. K.; Pedersen, L. H. (2007): "Market Liquidity and Funding Liquidity", Review of Financial Studies, Vol. 22 (6), 2201-2238. http://dx.doi.org/10.1093/rfs/hhn098

Caporin, M.; Pelizzon, L.; Ravazzolo, F.; Rigobon, R. (2013): "Measuring sovereign contagion in Europe", NBER Working Paper 18741.

Chen, Y. (1999): "Banking Panics - The Role of the First-Come, First-Served Rule and Information Externalities", The Journal of Political Economy, Vol. 107 (5), 946-968. http://dx.doi.org/10.1086/250086

Constâncio, V. (2012): "Contagion and the European debt crisis", Financial Stability Review, Vol. 16, $109-121$.

De H., Jakob; Mink, M. (2012): "Contagion during the Greek Sovereign Debt Crisis", DNB Working Paper No. 335.

De Santis, R., (2012): "The euro area sovereign debt crisis - safe haven, credit rating agencies and the spread of the fever from Greece, Ireland and Portugal", European Central Bank Working Paper 1419.

Dornbusch, R., Park, Yung C., Claessens, S.., (2000): "Contagion: Understanding How it Spreads", The World Bank Research Observer, Vol. 15, 177-197. http://dx.doi.org/10.1093/wbro/15.2.177

Drakos, A. A.; Kouretas, G. P.; Zarangas, L. P. (2010): "Forcasting financial volatility of the Athens Stock Exchange daily returns: An application of the asymmetric normal mixture GARCH model", International Journal of Finance and Economics, Vol. 15, 1-4.

Eijffinger, Sylvester C.W. (2012): "Rating Agencies: Role and Influence of Their Sovereign Credit Risk Assessment in the Eurozone", Journal of Common Market Studies, Vol. 50 (6), 912-921. http://dx.doi.org/10.1111/j.1468-5965.2012.02289.x

Engle, R. F. (1982): "Autoregressive Conditional Heteroscedasticity with Estmates of the Variance of United Kingdom Inflation", Econometrica, Vol. 50 (4), 987-1007. http://dx.doi.org/10.2307/1912773

Engle, R. F. (2002): "Dynamic Conditional Correlation: A Simple Class of Multivariate Generalized Autoregressive Conditional Heteroskedasticity Models", Journal of Business and Economic Statistics, Vol. 20, 339-350. http://dx.doi.org/10.1198/073500102288618487

Engle, R. F.; Kroner, Kenneth F. (1995): "Multivariate Simultaneous Generalized ARCH", Econometric Theory, Vol. 11, 122-150. http://dx.doi.org/10.1017/S0266466600009063

Engle, R. F.; Sheppard, Kevin (2001): "Theoretical and Empirical Properties of Dynamic Conditional Correlation Multivariate GARCH", NBER Working Paper w8554.

European Parliament (2011): "Rating Agencies - Role and Influence of their Sovereign Credit Risk Assessment in the Euro Area", European Parliament Policy Department Economic and Scientific Policy, 1-84. 
Forbes, K. J.; Rigobon, R., (2001): "Contagion in Latin America: Definitions, Measurement, and Policy Implications", Economia, Vol. 1 (2), 1 - 46. http://dx.doi.org/10.1353/eco.2001.0001

Forbes, K. J.; Rigobon, R., (2002): "No Contagion, only Interdependence: Measuring Stock Market Co-movements", Journal of Finance, Vol. 57(5), 2223-2261. http://dx.doi.org/10.1111/0022-1082.00494

Forbes, K. J. (2012): "The 'Big C': Identifying and Mitigating Contagion", MIT Sloan Research Paper No. 4970-12.

Fratzscher, M., (2003): "On Currency Crises and Contagion", Journal of Finance and Economics, Vol. 8 (2), 109 129. http://dx.doi.org/10.1002/ijfe.203

Giordano, R.; Pericoli, M.; Tommasino, P. (2013): "Pure or Wake-up-Call Contagion? Another Look at the EMU Sovereign Debt Crisis", Bank of Italy Working Paper No. 904.

Goldstein, M. (1998): "The Asian Financial Crisis - Causes, Cures and Systemic Implications", Washington.

Gorea, D.; Radev, D., (2013): "The Euro Area Sovereign Debt Crisis: Can Contagion Spread from the Periphery to the Core?", Gutenberg School of Management and Economics Discussion Paper No. 1208

Kaminsky, G. L.; Reinhart, C. M.; Vegh, C. A. (2003): "The unholy trinity of financial contagion", NBER Working Paper Series 10061, http://www.nber.org/papers/w10061.

King, M. and Wadhwani, S. (1990): "Transmission of Volatility between Stock Markets", The Review of Financial Studies, Vol. 3, 5-33. http://dx.doi.org/10.1093/rfs/3.1.5

Leung, W. S.; Taylor, N. (2013): "Testing for contagion: the impact of US structured markets on international financial markets", Handbook of Research Methods and Applications in Empirical Finance, 256-284.

Longstaff, F. A. (2010): "The subprime credit crisis and contagion in financial markets", Journal of financial economics, Vol. 97(3), 436-450. http://dx.doi.org/10.1016/j.jfineco.2010.01.002

Masson, P. (1999): "Contagion - Monsoonal Effects, Spillovers, and Jumps between Multiple Equilibria, Agénor, Pierre-Richard, Marcus Miller, David Vines and Axel Weber (Pub.): The Asian Financial Crisis - Causes, Contagion and Consequences, Cambridge, 265-283.

Mink, M. and de Haan, J., (2012): "Contagion during the Greek Sovereign Debt Crisis", DNB Working Paper, No. 335, Amsterdam.

Missio, S.; Watzka, S., (2011): "Financial contagion and the European debt crisis", CESifo working paper: Monetary Policy and International Finance 3554, http://hdl.handle.net/10419/49518, 03.12.2012.

Nelson, D. B. (1991) "Conditional Heteroskedasticidy in Asset Returns: A New Approach", Econometrica, Vol. 59 (2), 347-370. http://dx.doi.org/10.2307/2938260

Pericoli, M.; Sbracia, M., (2003): "A Primer on Financial Contagion", Journal of Economic Surveys, Vol. 17 (4), 571 608. http://dx.doi.org/10.1111/1467-6419.00205

Reisen, H.; von Maltzan, J., (1999): "Boom and Bust and Sovereign Ratings", OECD Development Centre Working Paper 148.

Sy, Amadou N. R. (2009): "The Systemic Regulation of Credit Rating Agencies and Rated Markets", IMF Working Paper 09/129. 
Financial contagion during the European sovereign debt crisis

Sweets, JEFS (2016), 04(02), 46-59

Appendix

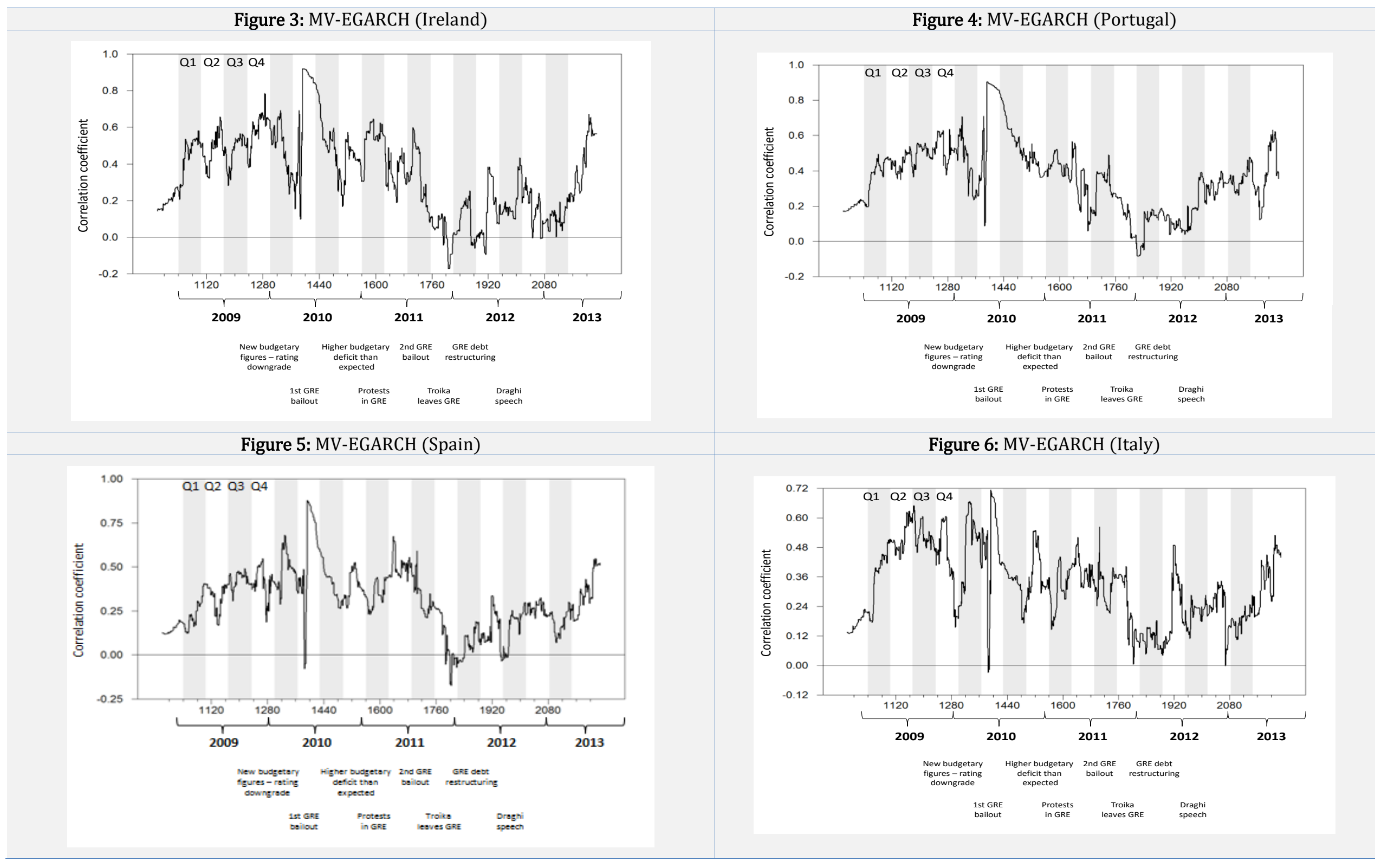

Journal of Economic and Financial Studies

Page 57 
Figure 7: MV-EGARCH (Germany)

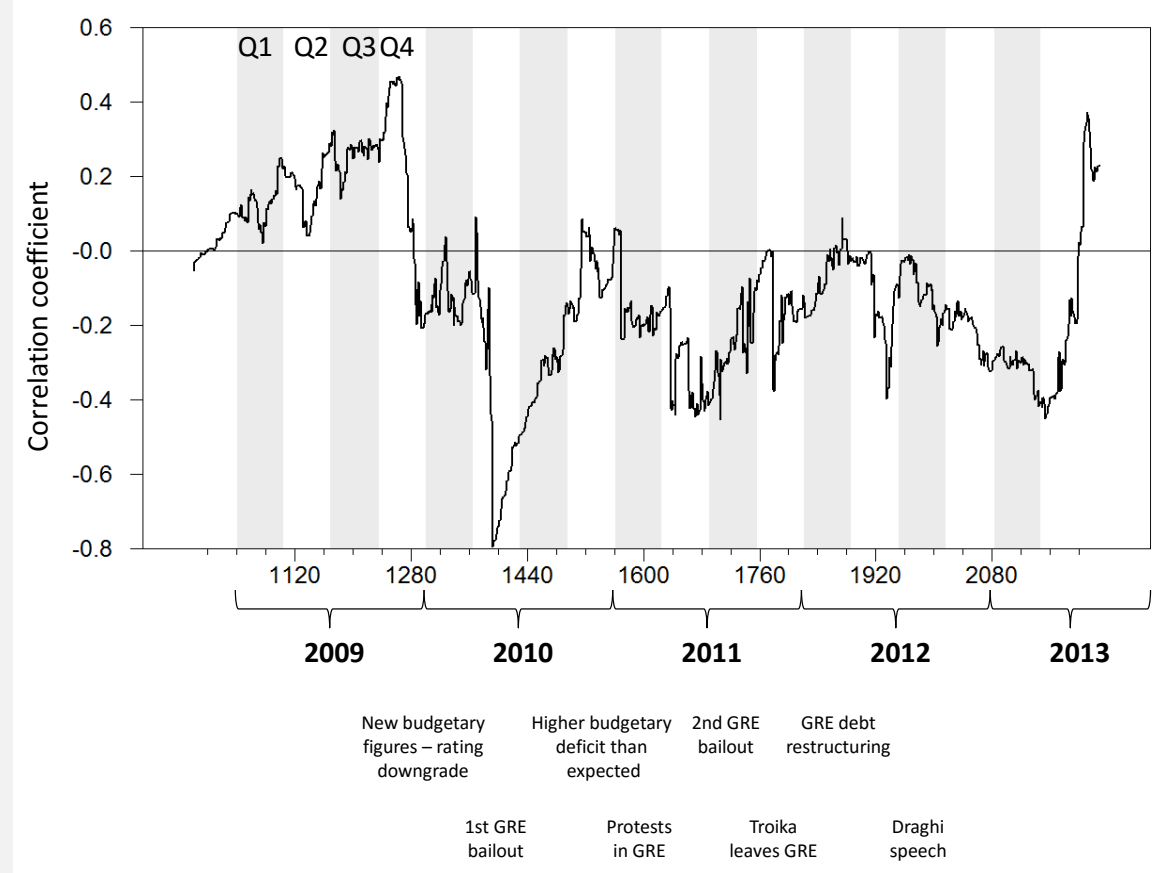

Figure 8: MV-EGARCH (Austria)

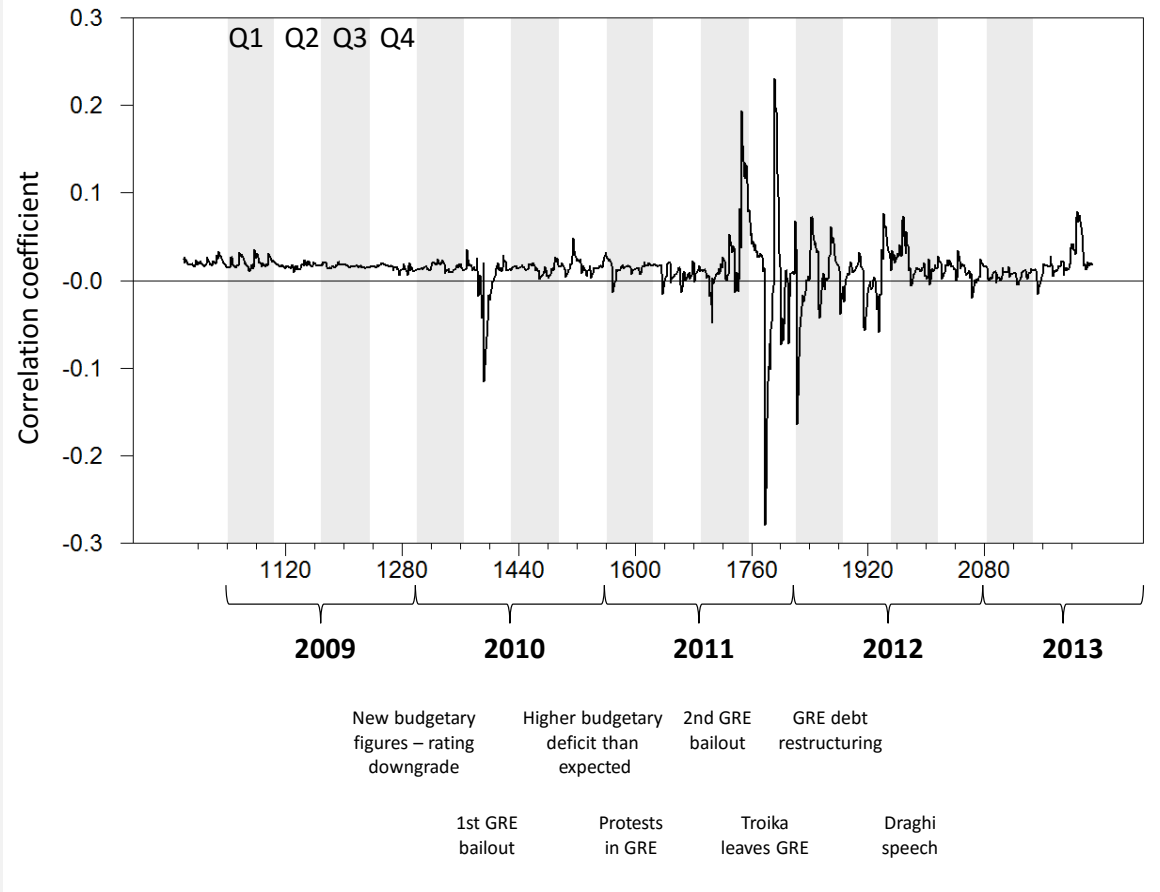


Table 2: Rating announcements concerning Greece

\begin{tabular}{|l|l|l|l|}
\hline \multicolumn{1}{|c|}{ Date } & Fitch & S\&P & Moody's \\
\hline 8 Dec. 2009 & BBB+ & & \\
\hline 16 Dec. 2009 & & BBB+ & \\
\hline 22 Dec. 2009 & & & A2 \\
\hline 27 Apr. 2010 & BBB- & BB+/B & A3 \\
\hline 14 June 2010 & & & Ba1 \\
\hline 7 Mar. 2011 & & & B1 \\
\hline 30 Mar. 2011 & & BB- & \\
\hline 9 May 2011 & & B & \\
\hline 20 May 2011 & B+ & & \\
\hline 1 June 2011 & & & Caa1 \\
\hline 14 June 2011 & & CCC & \\
\hline 13 July 2011 & CCC & & \\
\hline 25 July 2011 & & & Ca \\
\hline 27 July 2011 & & CC & \\
\hline 22 Feb. 2012 & C & & \\
\hline 27 Feb 2012 & & SD & \\
\hline 3 Mar. 2012 & & & C \\
\hline 9 Mar. 2012 & RD & & \\
\hline 13 Mar. 2012 & B- & & \\
\hline 2 May 2012 & & CCC & \\
\hline 17 May 2012 & CCC & & \\
\hline
\end{tabular}

Table 3: Crisis news

\begin{tabular}{|c|c|}
\hline Date & Events \\
\hline 2010/05/05-06 & $\begin{array}{l}\text { The EU and the IMF agree to a } € 110 \text { billion bailout package for Greece } \\
\text { (First Greek bailout) }\end{array}$ \\
\hline 2010/05/10 & Establishment of EFSF: A $€ 750$ billion emergency fund is created \\
\hline 2010/11/30 & $\begin{array}{l}\text { The EU and the IMF approve of an } € 85 \text { billion rescue package for Ireland } \\
\text { Statement of the Eurogroup on ESM loans }\end{array}$ \\
\hline 2011/05/06 & $\begin{array}{l}\text { Portugal accepts } € 78 \text { billion rescue package } \\
\text { Eurogroup discusses Greek financial situation and rejects Greek exit of the Eurozone }\end{array}$ \\
\hline 2011/07/04 & Italy`s financial situation deteriorates \\
\hline 2011/07/08 & Greece receives next credit tranche \\
\hline 2011/07/21 & The EU agrees on a $€ 159$ billion additional bailout package for Greece (Second Greek bailout) \\
\hline 2011/08/04-05 & $\begin{array}{l}\text { Spain and Italy come under pressure: } 10 \text {-year Italian government bond yields rocket to } 6.2 \% \text {. } \\
\text { Berlusconi proposes } € 45 \text { billion in spending cuts and tax increases }\end{array}$ \\
\hline 2011/08/25 & Spain`s financial situation worsens \\
\hline 2011/09/01-02 & $\begin{array}{l}\text { Greece misses austerity targets. Troika leaves Greece } \\
\text { Italy`s financial situation deteriorates further }\end{array}$ \\
\hline $2011 / 10 / 28$ & Agreement on Greek debt rescheduling \\
\hline 2011/11/08 & Government crisis in Athens. National referendum is announced \\
\hline $2011 / 11 / 22$ & Greece`s new government announces austerity budget \\
\hline $2011 / 11 / 29$ & Greece receives next credit tranche \\
\hline 2011/12/02 & Strikes and demonstrations take place in Greece \\
\hline 2012/01/12 & Mario Monti becomes prime minister in Italy \\
\hline 2012/03/08 & Greek debt rescheduling reaches eventual success. Substantial haircut of more than 50 percent \\
\hline 2012/03/16 & New rescue package for Greece (Revised second Greek bailout) \\
\hline 2012/06/27 & $\begin{array}{l}\text { Greece urges for additional time to meet financial obligations } \\
\text { New government elections in Greece }\end{array}$ \\
\hline
\end{tabular}

